\title{
Cuevas en ríos de bloques y cañones techados en rocas plutónicas del NW/W de la Península Ibérica
}

\author{
Caves under rivers of blocks and roofed canyons in \\ plutónicas rocks from NW / W of the Iberian Peninsula
}

VAQUEIRO-RODRÍGUEZ, M., VIDAL-ROMANÍ, J.R.

${ }^{1}$ Instituto Universitario de Xeoloxía “Isidro Parga Pondal”, Universidade de A Coruña

Clube de Espeleoloxía “A Trapa", Vigo

https://doi.org/10.17979/cadlaxe.2018.40.0.4918

enviado 5/8/2018 aceptado $12 / 12 / 2018$

\section{Resumen}

Se describen los nueve tipos morfológicos de cuevas desarrolladas en rocas plutónicas que se han diferenciado hasta ahora. De todos ellos los tipos cueva de río de bloques y cueva de cañón de erosión techado son los tienen mayores dimensiones y mayor desarrollo longitudinal. Se presentan doce casos de sistemas de cuevas situados en el W y NW de la Península Ibérica y localizados en España, (A Coruña, Cáceres, Lugo, Ourense y Pontevedra), y en Portugal, (Vila Real, región Norte). Esto nos permiten mostrar el fenómeno a distintas escalas, revisar y esquematizar los distintos procesos que ocurren e interaccionan en este particular medio.

Palabras clave: Pseudokarst, plutónicas, sistemas de cuevas, ríos de bloques 


\begin{abstract}
The nine morphological types of caves developed in plutónicas rocks that have been defined so far. Erosion canyon roofing are the largest and have greater longitudinal development. There are twelve cases of cave systems located in the W and NW of Iberian Peninsula and located lither in Spain, (A Coruña, Cáceres, Lugo, Ourense and Pontevedra), and in Portugal, (Vila Real, North region). This allows us to show the phenomenon at different sizes to review and outline the different processes that occur and interact in this particular enviroment.
\end{abstract}




\section{INTRODUCCIÓN}

Son muchas las definiciones que se han dado para la micro, meso o macroforma cueva: En 1953, Stone definía "cueva" como "cualquier cavidad natural bajo la superficie terrestre, cuyas dimensiones son medibles en pies (o metros), cuyas paredes son substrato rocoso, y que generalmente se extienden en una oscuridad absoluta". También CHABERT Y COURBON (1997) en la primera edición del Atlas Mundial de cuevas en rocas no solubles, las definen como un "espacio natural subterráneo de tamaño suficiente para que acceda el ser humano". Obviamente estas definiciones no vinculan el concepto cueva a ningún tipo de roca y tampoco limitan su formación a un proceso genético específico.

Aunque tradicionalmente las cuevas se suelen asociar a las rocas solubles, la realidad es que no son exclusivas de las zonas kársticas. Son frecuentes en la mayoría de los tipos de rocas (BOSTON, 2004) y existen en regiones carentes de karst (Urban Y Oteska, 1998). Ocurre así en la naturaleza, de manera evidente, que "determinadas formas generadas como resultado de una acción geodinámica cualquiera, se presentan en rocas de diferente composición y con idénticas características geométricas" (Eraso y Pulina,1994).

La existencia de cuevas en rocas magmáticas (volcánicas o eruptivas, y plutónicas) es poco conocida. Vaqueiro-Rodríguez \& Vidal-Romaní (2014), aplicando el criterio de Wheeland (PCC, 2007), han revisado y actualizado la relación de cuevas en rocas plutónicas incluida en el atlas de Chabert \& Courbon (ib), recopilando más de 286 referencias sobre cuevas en granitos y gneis de cierta entidad, distribuidas en 37 países de cinco continentes. En una segunda revisión bibliográfica (Vaqueiro-Rodríguez, 2017), se han localizado más de 500 referencias sobre cuevas en rocas magmáticas (ver figura 1). Las cavidades inventariadas son micro o mesoformas de las que el 50\% tiene menos de $100 \mathrm{~m}$ de desarrollo lineal, el 80\% tienen menos de $300 \mathrm{~m}$ de desarrollo lineal, y tan sólo un 4\% de ellas supera los $1.000 \mathrm{~m}$ de desarrollo lineal total.

Son varios los tipos morfológicos de cavidades desarrolladas en rocas plutónicas. Para nosotros, y entendida la cueva como una forma, su clasificación atenderá más a los rasgos morfológicos principales y a la evolución del macizo dónde se encuentran, que a los procesos genéticos asociados. Así, Vaqueiro-Rodríguez (2017), tomando como referencia la síntesis de tipos propuesta por VIdal-Romaní \& Vaqueiro-Rodríguez (2007), quienes retoman además la exposición de Vidal-Romaní \& Twidale (1998: 305-334) y Twidale \& Vidal-Romaní (2005), e incorporando la modificación sugerida por Kolawole \& Anifowose (2011), define nueve tipos morfológicos de cavidades en rocas magmáticas. En este trabajo agrupamos estos nueve tipos en tres grandes grupos atendiendo a la continuidad de los límites de los pasajes y de los volúmenes subterráneos:

\section{Cavidades con límites continuos:}

1. Cuevas tafone, cavidades de bloque único y límites continuos, vinculadas a la etapa de deformación elástica del macizo durante la fase de emplazamiento del cuerpo magmático.

2. Cuevas lapa (sheet tafoni), cavidades de límites continuos, emplazadas en el interior de las bandas de cizalla intercaladas en las estructuras de lajas. 
Presentan sección elíptica, progresando confinada entre los límites de la banda dónde se emplaza.

3. Cuevas de erosión marina, que en general son cuevas de tipo estructural, asociadas mayoritariamente a discontinuidades verticales o subverticales, y desarrolladas por explotación directa y ensanchamiento de la discontinuidad o por explotación de los depósitos antiguos que rellenan esas discontinuidades. También se han identificado cuevas formadas por la erosión marina de un granitoide alterado, y cuevas formadas por la explotación de la discordancia entre la plataforma y los depósitos de costa que la fosilizan.

\section{Cavidades con límites semi-continuos:}

1. Cuevas estructurales, o cavidades asociadas a diaclasas, fracturas o discontinuidades generalmente verticales o subverticales. Cuevas de límites parcialmente continuos (los labios de la discontinuidad), con techos generalmente discontinuos, parcialmente abiertos $\mathrm{y}$ caracterizados por la presencia de bloques.

2. Cañones techados (ríos de bloques sobre cañones).

\section{Cavidades con límites discontinuos:}

1. Cuevas asociadas a estructuras de lajas, y determinadas principalmente por los planos de foliación o lajamiento.

2. Cuevas formadas por la acumulación de bloques. Se distinguen tres subtipos en base a las particularidades del campo de bloques y a la geometría de los bloques:
1. Cuevas asociadas a ríos de bloques, esto es, a acumulaciones de bloques en el fondo de un valle, caracterizada por su extensión lineal (siguiendo el propio valle) y por la interacción entre el caos de bloques y las aguas en circulación por el propio valle.

2. Cuevas asociadas a mares de bloques, esto es, a acumulaciones de bloques de gran extensión.

3. Cuevas formadas por acumulaciones de bloques con poco movimiento, "in situ" producidas por fenómenos de creep rocoso o reptación.

De toda ellas, las cuevas en ríos de bloques y su variante estructural, las cuevas en cañones techados, son los tipos morfológicos de cuevas en rocas plutónicas que presentan las mayores dimensiones en cuanto a desarrollo y volumen. Ambos tipos forman complejos sistemas de cavidades, que son el tema central de este trabajo.

\section{CUEVAS EN RÍOS DE BLOQUES Y CUEVAS EN CAÑONES TECHADOS.}

Cuando se producen movimientos en los escarpes o vertientes, lo más habitual es que la masa de bloques movilizados alcance el fondo del valle, enterrándolo a medida que se extiende a lo largo de él. Se forman así acumulaciones de bloques de cierta potencia, dónde los espacios subterráneos definidos entre los bloques, entre los bloques y el substrato, y entre los bloques y el lecho rocoso, configuran los sistemas de cuevas que hemos denominado ríos de bloques.

En muchos de estos valles, pueden existir manantiales o cursos activos de distinta entidad que quedan parcialmente enterrados 
bajo la avalancha de bloques. En estos casos el curso subterráneo queda confinado a circular por los huecos que se producen entre los bloques caídos, buscando la solución de continuidad de mínima energía a lo largo del fondo del valle. Resulta así un curso generalmente anastomosado que suele presentar una surgencia al pie de la colada de bloques (ver figura 2).

Los espacios subterráneos que definen el curso y los niveles de pasajes suprayacentes, están delimitados generalmente por bloques rotos de superficies ásperas, aunque también cuando los cursos presentan caudales importantes, los pasajes activos pueden presentar superficies pulidas tanto por la erosión de los bloques caídos, como por exhumación del propio lecho rocoso. En muchos de estos casos el lecho rocoso ya presentaba superficies pulidas y formas de erosión antes de quedar enterrado bajo la acumulación de bloques.

Puede ocurrir además que la masa de bloques movilizados entierre y rellene un cañón en roca. Inclusive que el impacto de los bloques caídos provoquen la rotura de los escarpes del cañón. Se forma así lo que hemos denominado un cañón techado. En estos cañones los niveles superiores son morfológicamente similares a los ríos de bloques. Y dentro del cañón, existirán niveles y pasajes formados por bloques rotos, pero también paleoniveles caracterizados por sus terrazas en roca con formas de erosión elevadas con respecto al curso actual.

El curso subterráneo queda entonces definido unívocamente por la traza del cañón original. Durante su etapa aérea estos cañones eran canales abiertos de paredes sinuosas y pulidas, de traza lineal o poligonal en el que podían abundar las distintas formas de erosión. Una vez enterrados, y en función de su amplitud, del tamaño de los bloques, y de que colapse parcialmente el escarpe del propio cañón, el curso subterráneo pasará a funcionar como un conducto cuasi-cerrado, dónde el río circulará confinado bien como corriente única en los tramos dónde se preserve el cañón, o como curso anastomosado entre la red de bloques dónde se rellene o haya colapsado el cañón.

En la mayoría de estos sistemas, sean ríos de bloques o cañones techados, existe una zona que actúa como sumidero, una acumulación de bloques que mantiene el curso de agua confinado y subterráneo, y una zona dónde se produce la surgencia nuevamente a superficie. Por tanto estas cuevas funcionan como sistemas de transfluencia drenando total o parcialmente un curso superficial.

Vaqueiro-Rodríguez (2017) ha descrito estas cuevas como formas poligénicas debido a que lo normal es que concurran dentro de un mismo espacio subterráneo, tramos de cueva estructurales (asociados a diaclasas, fallas o fisuras), con tramos formados exclusivamente por bloques, e incluso tramos que conserven lapas o tafoni enterrados. La prevalencia de un rasgo morfológico es lo que nos llevará a clasificar a una cueva o sistema dentro de uno u otro tipo morfológico. Y también han sido caracterizados como formas polifásicas debido a que la morfología actual es el resultado de distintas etapas de colapso o de movilización de los bloques. Además, a partir de las secuencias y alternancias de procesos deposicionaleserosionales, con fosilización y reexcavación de canales, niveles, pasajes o paleoniveles, se observa cómo algunos cursos subterráneos han cesado su circulación temporalmente para después reactivarse. Alternancias que en algunas cuevas parecen haber ocurrido cíclicamente, bien asociados con eventos 
climáticos, o bien como consecuencia de las distintas fases de movilización de los bloques.

\section{CAVIDADES EN GRANITOS EN EL W Y NW DE LA PENÍNSULA IBÉRICA}

Con el objeto de mostrar el fenómeno a distintas escalas, describimos brevemente 12 cavidades desarrolladas en granitos, todas ellas micro o mesoformas de cierta relevancia, localizadas en el W y NW de la Península Ibérica. Ver figura 3.

\section{Sistema do Río Calva, Sta Valha, Valpaços, Portugal}

Se trata de un pequeño curso subterráneo de unos $80 \mathrm{~m}$ de desarrollo y $9 \mathrm{~m}$ de desnivel, y que drena el río Calva en Santa Valha (Portugal) a lo largo de un canal en roca techado por bloques caídos. Este canal queda definido por una sucesión de marmitas coalescentes parcialmente rotas, de tamaño decreciente desde el sumidero (punto de salto) hasta la surgencia. Ver figura 4. Los bloques que entierran el canal provienen del colapso del escarpe rocoso de la cara interior de un meandro del río. (com. pers. D. Augusto Lage, 2018, vecino de Valpaços).

\section{Sistema de A Porteliña, Valadares, Vigo (Pontevedra), España}

Es un pequeño río de bloques de 105 $\mathrm{m}$ de desarrollo total y $6,5 \mathrm{~m}$ de desarrollo vertical formado tras el colapso de una vertiente, que entierra parcialmente una lapa subhorizontal. Algunos de los bloques rotos son tafoni de tamaño métrico. Asociado a esta lapa nace un arroyo que se suma al pe- queño curso subterráneo de la vaguada de A Porteliña, formando uno de los pequeños afluentes secundarios del río Rego da Rega. El agua circula entre los bloques rotos o dislocados a lo largo de un canal poligonal definido por los bloques. No existen apenas trazas de erosión y transporte, e inclusive existen depósitos de gravas y fragmentos de roca angulosos fosilizados por una colada de pigotita que cubre el fondo del curso. Este bioespeleotema actualmente está siendo destruido por la escasa erosión del arroyo. Los techos de la lapa y las zonas afectas por capilaridad en la base de muchos bloques próximos al curso subterráneo, presentan importantes conjuntos de bioespeleotemas de ópalo-A. La cavidad es yacimiento arqueológico (Alonso-Cuevas et al., 1997).

\section{Sistema de A Cunchosa, Aldán, Cangas (Pontevedra), España}

Conjunto de cavidades formadas por el colapso de un escarpe rocoso sobre un valle en el lugar de A Cunchosa, al norte de Aldán (Cangas). La cavidad principal tiene un desarrollo topografiado total de $174 \mathrm{~m}$, y un desarrollo vertical de $-7.5 \mathrm{~m}$. Presenta un curso activo de poca intensidad, pero con mayor desarrollo y continuidad que el de A Porteliña. Este curso subterráneo circula anastomosado entre la red de bloques, alternando tramos con fondo rocoso, con tramos formados por gravas, arenas y cantos subangulosos. No hay evidencias de rodadura. Destaca nuevamente la presencia de algunos tramos de curso que circulan sobre depósitos de pigotita erosionados, con morfología de flujo cubiertos por microgours superpuestos, aunque en realidad son brechas de cantos y gravas con matriz de pigotita. Destaca la profusión de bioespeleotemas de 
ópalo-A en todos los niveles de la cavidad, algunos con un importante tamaño (ver figura 5). La cavidad es también yacimiento del Neolítico-Bronce (SUAREZ OTERO, 1997).

\section{Sistema de O Cibro, Monte Pindo, Carnota (A Coruña), España}

Río de bloques formado en una vaguada que presenta un curso de carácter torrencial. El desnivel entre el sumidero y la surgencia se ha estimado en $60 \mathrm{~m}$. No se disponen de datos sobre el desarrollo total. En general los bloques son de dimensiones métricas a decamétricas pero la acumulación en el fondo del valle es de poca potencia, y las cuevas presentan poca continuidad. Los mayores volúmenes subterráneos y con mayor continuidad se localizan en las proximidades del sumidero y serían pasajes semitechados de carácter estructural. Fuera de este tramo estructural, no existe un canal definido. En período estival el curso se presenta relativamente concentrado, si bien tiende a circular anastomosado entre la red de espacios definidos por los bloques. En el interior de las cavidades se han observado algunos tafoni. Nuevamente destacan los espeleotemas de ópalo-A y que en algunas zonas forman grandes depósitos tipo manto (grass-shape). Puntualmente se han identificado retazos de depósitos de pigotita. La cueva es yacimiento arqueológico con materiales del Calcolítico-Bronce y Edad Media.

\section{Sistema de Adeghas o Los Soterrados, Parto- via, Carballiño (Ourense), España}

Cañón techado que funciona como sistema de transfluencia para el río Barón en las proximidades de Partovia. Está asociado a una falla activa de dirección $\mathrm{N} 40^{\circ} \mathrm{E}$. Hasta ahora solamente se han topografiado $195 \mathrm{~m}$ de pasajes (11 m de desnivel) correspondientes a los niveles altos de la cavidad próximos al sumidero. Mediante GPS se ha estimado un desnivel entre el sumidero y la surgencia de $35 \mathrm{~m}$ y un curso subterráneo con más de $300 \mathrm{~m}$ de desarrollo proyectado.

Es el único sistema que hemos estudiado en falla activa. Presenta un elevado número de epicentros localizados en el entorno de la cueva. En profundidad nos encontramos un curso parcialmente encañonado, similar a la de otros sistemas descritos, si bien las marmitas están rotas y los bloques que definen el cañón parcialmente desplazados, lo que muestra que el colapso afectó a la totalidad del talud y no solamente a las zonas más altas del escarpe

La cavidad presenta depósitos de ópaloA principalmente en los niveles altos. Se han identificado numerosos materiales arqueológicos (ver figura 6) adscritos principalmente al Neolítico y Bronce, aunque también se han localizado varias tégulas planas, varias ruedas de molino de mano (en profundidad), y fragmentos de ruedas de molino de gran tamaño (proximidades de bocas). También dentro de las cuevas se localizan fragmentos de tafoni y bloques tafone.

\section{Sistema de O Folón, Fragoselo, Vigo (Ponte- vedra), España}

Este cañón techado actúa como sistema de transfluencia para el río Rego da Rega, que circula subterráneo durante unos 235 $\mathrm{m}$ a su paso por Fragoselo. Se adaptada en general a la banda de cizalla asociada a una falla de desgarre de dirección $\mathrm{N} 170^{\circ} \mathrm{E}$ (Hoja MAGNA50 - 223, Rubio-Navas et al., 1978), y a las familias de diaclasas asocia- 
das, que cortan subverticalmente la estructura de foliación local. Tiene un desarrollo topografiado de $925 \mathrm{~m}$ y $32 \mathrm{~m}$ de desnivel. Presenta una estructura de curso policíclico con desplazamientos y encajonamientos sucesivos del curso de aguas, lo que da lugar a la existencia de tramos de curso abandonado, elevados sobre el curso actual y que se pueden seguir a lo largo de todo el sistema. Los desplazamientos laterales del curso y su encajonamiento se producen a favor de distintas familias de discontinuidades subverticales. Internamente el sistema progresa salvando saltos asociados a fracturas de dirección aproximada $\mathrm{N} 30^{\circ} \mathrm{E}$ (con buzamiento $70^{\circ}-\mathrm{N} 60^{\circ} \mathrm{W}$ ), con un curso definido en discontinuidades de direcciones $\mathrm{N} 60^{\circ} \mathrm{E}, \mathrm{N} 60^{\circ} \mathrm{W}$ y $\mathrm{N} 160^{\circ} \mathrm{E}$, siendo en conjunto un cañón relativamente estrecho de planta sinuosa. En algunos puntos de la cueva el cañón conserva un canal en U con un desarrollo vertical que supera los $10 \mathrm{~m}$ de altura (ver figura 7). Una de las particularidades del sistema es la presencia de varios paleoniveles, que definen conductos con sección tipo key-hole adaptados al buzamiento de la estructura de lajas, y a la intersección de esta con la falla que guía el sistema. (Vaqueiro-Rodríguez, 2003; Vaqueiro-Rodríguez et al., 2006).

En su curso medio existe una dolina de hundimiento en torno a la que se circunscriben los principales yacimientos arqueológicos de esta cueva, con dataciones que alcanzan los 9,46 \pm 1,26 kaBP (Sanjurjo-Sánchez, 2013). Aguas arriba del colapso se han identificado ritmitas lacustres que podrían representar una etapa de estancamiento del curso subterráneo tras un gran colapso que dio lugar a la formación de una gran dolina. Destaca también la existencia de una colada de pigotita con gours superpuestos, algunos de tamaño decimétrico. Fue el primer depó- sito de pigotita datado, mostrando una edad exterior de 2.140-2.400 cal.yrBP (Vidal-Romaní et al., 2010) .

\section{Sistema de A Trapa, Ribadelouro, Tui (Pon- tevedra), España}

Es por ahora la cavidad en granitos más grande (en desarrollo) de las estudiadas. Tiene un desarrollo total topografiado de $1.618 \mathrm{~m}$, con un desnivel de $102 \mathrm{~m}$ entre el sumidero y la surgencia. El sistema presenta gran continuidad, aunque existen varios puntos en los que las dimensiones físicas de los pasajes no permiten recorrer la totalidad del curso subterráneo.

Este sistema se formó a partir de un deslizamiento rocoso para el que se han estimado más de $110.000 \mathrm{~m} 3$ de roca, y que podría estar asociado a una falla inversa que parece guiar la rotura y desplazamiento de los bloques en los paleocursos subterráneos del curso subterráneo medio (Vaqueiro-Rodríguez, 2017). El deslizamiento enterró parcialmente al río S. Simón, desplazándolo y elevándolo de cota con respecto al curso primitivo. Así, en la actualidad, el valle presenta dos cursos circulando en diferente posición: Uno subterráneo, y que trazaría aparentemente el curso primigéneo del S. Simón; y otro superficial, que rodea el frente del deslizamiento de bloques en una cota más alta, por el que circula el agua que no es capaz de transferir el sumidero de A Trapa.

Estas cuevas presentan depósitos de ópalo-A en los niveles más alejados del río, inclusive depósitos de microestromatolitos terrestres (Wright, 1989) de ópalo biogénico. En el tramo central se desarrollan importantes depósitos de pigotita, destacando formas de flujo (coladas) de más de $8 \mathrm{~m}$ de altura, 
formas de goteo (dripstone) y formas compuestas flujo-goteo (draperies). Las superficies de todas estas microformas, inclusive las que presentan pendientes extraplomadas, están cubiertas por microgours de tamaños milimétricos a decimétricos. Las dataciones de una columna estalagmítica evidencian un crecimiento continuo de este depósito entre el 3760-2960 cal.yrBP (núcleo) y el 27502050 cal.yrBP (superficie visible) (Vidal-Romaní et al., 2010). Esta colada cubre incluso las marmitas, paredes (ver figura 8) y techos de una cascada subterránea. E inclusive forman un conglomerado con los depósitos de cantos rodados del lecho aguas abajo de este salto. Muchos de estos depósitos y microformas presentan actualmente la superficie pulida, inclusive han desarrollado acanaladuras (ver figura 9) y marmitas de pequeña entidad en su superficie, lo que sugiere nos encontramos en una fase de reactivación del curso subterráneo tras la fase de circulación lenta de agua y que permitió el desarrollo de estos depósitos.

En la cueva se han localizado numerosas piezas arqueológicas con dataciones entre $2.54 \pm 0.30 \mathrm{kaBP}$ y $7.05 \pm 0.86 \mathrm{kaBP}$ (Sanjurjo-Sánchez, 2013).

\section{Sistema de Albarellos o Susume, Beresmo, Avión (Ourense), España}

Es sin duda uno de los sistemas visualmente más espectaculares durante el estiaje del río Avia. En la actualidad este sistema está afectado por el embalse de Albarellos, sito en su surgencia, y no es accesible cuando el nivel del embalse supera el 30\%. Los registros de la cuenca hidrográfica muestran caudales de entre los 2.000 1/s y los 212.000 1/s.

El sistema está definido en el contacto de dos estructuras de foliación convergentes. Es un gran cañón techado, ligeramente sinuoso, con una orientación $\mathrm{N} 130^{\circ} \mathrm{E}-\mathrm{N} 160^{\circ} \mathrm{E}$ y que canaliza el río Avia durante $295 \mathrm{~m}$ de longitud, salvando un desnivel de $36 \mathrm{~m}$. Hasta la fecha se han topografiado $951 \mathrm{~m}$ de galerías y pasajes, de las cuales una parte se corresponde con (paleo)niveles colgados durante el proceso de excavación-incisión del cañón. Se estima que el desarrollo topográfico total superará los $1.100 \mathrm{~m}$.

El rasgo más llamativo de esta cavidad son las formas de erosión, cuya coalescencia define el paisaje subterráneo. El cañón presenta una sección en $\mathrm{U}$ en unos tramos, en $\mathrm{Y}$ en otros, definiendo un canal de flujo único salvo en zonas rellenas o colapsadas. En su tramo principal supera los $11,5 \mathrm{~m}$ de altura (fondo de canal a bóveda) con un ancho medio de $5 \mathrm{~m}$ (ver figura 10). El sumidero es una cascada de $8 \mathrm{~m}$ de altura.

En algunas zonas de la cueva, en las paredes del cañón y asociadas con planos de fisura, se localizan restos de coladas y conglomerados de pigotita muy erosionados.

\section{Sistema Tronceda, Tronceda, Mondoñedo (Lugo), España}

La cueva canaliza el río Tronceda a lo largo de un cañón subterráneo de $195 \mathrm{~m}$ de desarrollo proyectado, y traza un gran meandro del río aparentemente definido en el contacto de las estructuras de foliación de tres domos graníticos. Se estima que el cañón alcanza los $-12 \mathrm{~m}$ por debajo de la acumulación de bloques. Los bloques que lo techan provienen en general de ambas vertientes, si bien en tramos predominan los deslizamientos y colapsos de una u otra estructura de foliación. Los bloques caídos son de gran tamaño, llegando a cubrir el ancho total del cañón. 
Muchos de los grandes bloques que techan el río, asientan sobre bloques redondeados de tamaño medio, y que a su vez apoyan sobre una terraza rocosa rota. Todo ello parece indicar existieron varias fases de movimiento en las vertientes algunas de gran energía. En profundidad el cañón presenta rotura de su escarpe con desplazamiento y rejuego de los bloques que conforman sus paredes.

Destaca especialmente una gran colada de pigotita que se han desarrollado en la vertical del cañón del curso medio (ver figura 11). Este tramo de cueva está caracterizado por sus formas de erosión, con marmitas de hasta $4 \mathrm{~m}$ de diámetro.

\section{Sistema de Las Potras, Montehermoso (Cá- ceres), España}

Este sistema parece definido localmente por una falla de dirección aproximada $\mathrm{N} 52^{\circ} \mathrm{E}$. Canaliza bajo tierra al arroyo del Bronco a lo largo de unos $350 \mathrm{~m}$ (com. pers. D. Juan Jesús Sáncehz-Alcón, 2014, vecino de Montehermoso). Canal subterráneo sinuoso de paredes pulidas y formado por la coalescencia de marmitas turbillonares de tamaño variable apreciándose inclusive formas que alcanzan los $5 \mathrm{~m}$ de diámetro. También se han identificado formas de erosión superpuestas, inclusive en bloques rotos, elevadas sobre el curso actual, lo que apunta a la existencia de algún paleonivel representativo de un estadio intermedio durante la incisión y excavación del canal. El curso se presenta techado, no habiéndose determinado que partes del sistema se corresponden a rejuegos propios (derrumbe del cañón) o a colapsos de la vertiente. Ver figura 12.

En los niveles más superficiales y en los abrigos rocosos situados próximos abundan los espeleotemas de ópalo-A. En el interior del sistema, próximo al curso activo, se han fotografiado retazos de una costra de pigotita. El sistema es yacimiento arqueológico.

\section{Sistema do Río Edo, Castro Caldelas, Ouren- se, España}

No se disponen de datos dimensionales. La localización y fotografías han sido facilitadas por espeleólogos del G.E.S. Irmandiños (com. pers. Carlos Ares, 2017). Se trata de un curso subterráneo en roca que evoluciona en la dirección $\mathrm{N} 153^{\circ} \mathrm{E}$, y que circula por un cañón subterráneo, sinuoso de paredes pulidas, y caracterizado por sus formas de erosión y marmitas coalescentes de diámetro métrico, pero gran altura. Ver figura 13.

\section{DISCUSIÓN: SÍNTESIS DE PROCESOS}

Se han estudiado ríos de bloques de pequeño desarrollo y potencia, pero también ejemplos que gradan progresivamente hacia formas más complejas, con mayor desarro1lo, hasta dar lugar a sistemas de dimensiones kilométricas. Esta gradación se relaciona con la circulación del agua a través de las fisuras, y por tanto está muy influenciada tanto por las características del curso de agua (gradiente hidráulico, caudal, ...) como por la capacidad de la propias discontinuidades para drenar el agua. Así muchos de estos sistemas actúan como colectores de transferencia (transfluencia), capturando todo o parte de un curso superficial. Las mayores cuevas de este tipo están definidas por cañones techados, asociados a ríos de elevado caudal y energía.

Esta gradación se relaciona también con el desarrollo de formas de erosión. Así, 
por ejemplo, las cuevas con pequeños manantiales y cursos de poca energía apenas presentan superficies pulidas o bloques redondeados. Sin embargo los cursos de pequeña entidad dan lugar a canales excavados en roca (incisos) en los que se alternan tramos (estructurales) con márgenes rectos (straight-walled) y tramos con márgenes ondulados (undullating walls), de paredes pulidas con presencia de pequeñas (en diámetro) formas de erosión. Por su parte los cursos de alta energía, con flujos predominantemente turbulentos y supercríticos, presentan formas de erosión (pot-hole) de tamaño decamétrico. En general, en su fase aérea, serían canales simples de flujo único con gradiente variable del lecho, con secciones incisas en escalón y con puntos de salto. Estos cambios en el gradiente dan lugar a tramos con diferente dinámica y morfología. Y la propia evolución del gradiente da lugar a la formación y abandono de terrazas en roca que definen antiguos niveles o paleoniveles.

Muchas de las grandes formas de erosión subterráneas (con su morfología actual) ya existían en la fase aérea. Están asociadas a etapas en las que los cursos funcionaban como canales abiertos con puntos de salto claramente definidos. Sin embargo durante la fase subterránea, debido al confinamiento del curso dentro de un "conducto" y a las variaciones de caudal que sufre a lo largo del año, la dinámica subterránea alterna entre un régimen vadoso cuando el caudal es inferior a la capacidad de transferencia, un régimen epifreático cuando el caudal está próximo al límite de la capacidad de transferencia, y freático cuando se supera la capacidad de transferencia y el sistema "desborda", pasando el río a circular simultáneamente bajo tierra y sobre la colada de bloques.
La caída de bloques en el interior del propio cañón represa el agua durante el régimen vadoso lo que falsea localmente el desnivel o gradiente en los puntos de salto. Todo ello implica obviamente otra dinámica fluvial diferente, con unos flujos también diferentes, lo que conlleva que las grandes formas de erosión dejan de evolucionar de la misma forma que en su etapa aérea.

La capacidad de erosión sigue estando presente: Aparecen bloques rotos con superficies pulidas, inclusive tafoni, integrados en techos o rellenando los antiguos canales, y sobre los que se desarrollan nuevas microformas de erosión como scallops, flutes, acanaladuras (estrías), etc. pero también aparecen formas poligénicas como los onglets pulidos.

La estimación del radio hidráulico y profundidad hidráulica en función de las dimensiones topográficas de los pasajes y de los caudales medios por período determinan que en su fase de canal abierto predomina un régimen de flujo supercrítico (número de Froude menor que 1) y turbulento. Cuando el pasaje funciona como conducto desbordado, las grandes turbulencias se producirán por encima de la acumulación de bloques. En este caso han de existir dos dominios de circulación diferenciados, uno muy rápido y violento en superficie, y otro confinado a través de la cueva sumergida, localmente con elevadas presiones, y que imitaría un régimen freático.

Cuando el cañón funciona como conducto vadoso, en los tramos en que exista circulación difusa (anastomosada) entre la red de bloques, se pueden producir flujos paralelos asimétricos que inducen, como ocurre en algunas estructuras hidráulicas artificiales, esfuerzos y vibraciones de energía significativa. Estas vibraciones se transmiten a través de la acumulación de bloques 
y substrato, pudiendo generar daños estructurales cuando alcanzan niveles elevados de energía. Por ejemplo en el sistema de Albarellos, durante las fases de carga del cañón tras el período de estiaje, se han medido aceleraciones de hasta $2,5 \mathrm{~m} / \mathrm{s} 2$, similares a la de un sismo de pequeña intensidad y que afectan localmente a la acumulación de bloques y a la estructura del cañón. Este mismo tipo de vibraciones, pero de menor intensidad han sido registradas en el sistema de A Trapa. Y también han sido observadas en Las Potras (com. pers. Juan Jesús Sánchez Alcón, 2018).

Un elemento común en todos estos sistemas es la presencia de espeleotemas. Depósitos de pigotita en los niveles más profundos y medios, y depósitos de ópalo-A, evansitaestruvita en los niveles medios y más altos de las cavidades.

Hablar de espeleotemas es hablar de aguas lentas. Flujos muy lentos para la pigotita. Y flujos a nivel capilar o microflujos para el ópalo-A. Y la distribución de los espeleotemas en la vertical del río de bloques parece gradar y representar esta diferenciación de flujos: Espeleotemas de ópalo en niveles superiores, rara vez en proximidades de cursos, salvo formas circunscritas a los niveles húmedos en la base de algunos bloques; espeleotemas de pigotita en los niveles medios y profundos.

Sin embargo estos espeleotemas, principalmente los de pigotita, están presentes dentro de cuevas caracterizadas por sus formas de erosión con cursos relativamente energéticos. Incluso existen brechas o conglomerados con matriz de pigotita emplazadas en niveles activos, y coladas de flujo con microgours superpuestos que fosilizan canales, marmitas, acanaladuras y superficies de paredes y techos en pasajes activos y cascadas.

Todo ello nos lleva el reconocer la existencia de unas etapas o períodos más o menos prolongados (hasta 1000 años en el caso de la columna estalagmítica de A Trapa) durante los que la circulación subterránea principal se vio interrumpida o modificada, permitiendo que se alcanzasen las condiciones específicas bajo las que si pueden desarrollarse estos depósitos.

Pero también se ha observado la re-excavación de esos conglomerados y brechas, la exhumación por erosión de paleosuelos fosilizados por pigotita, y el desarrollo de marmitas y acanaladuras sobre depósitos de pigotita situados en paleoniveles elevados a más de $6 \mathrm{~m}$ de altura sobre el curso actual. Todo ello nos lleva a considerar la existencia de períodos con flujos mucho más energéticos, y con caudales muy superiores a la capacidad de transferencia del sistema, o la de los espacios dónde se han desarrollado esos depósitos.

Necesariamente, esta coincidencia física de formas incompatibles nos describe un medio cambiante, y por tanto la existencia de estos espeleotemas no es algo banal: En algunos casos la formación y destrucción de los depósitos están relacionados con cambios sustanciales en la estructura de la cueva, como es el caso de la formación de la dolina de O Folón; pero también podría ser reflejo del cambio de las condiciones climáticas exteriores, y que se muestran en la cueva, en esa alternancia de etapas de cese-reactivación de los diferentes procesos subterráneos. Hipótesis nada descartable por cuanto los modelos dinámicos microclimáticos propuestos en Vaqueiro-Rodríguez (2017) concluyen que el microclima subterráneo para las cavidades en rocas plutónicas de límites semi-continuos y discontinuos 
es un reflejo cuasi-síncrono del clima exterior. Además, si comparamos las dataciones obtenidas a partir de los distintos depósitos con las secuencias de eventos paleoclimáticos obtenidos por Railsback et al. (2011) para el NW de la península Ibérica a lo largo del Holoceno (ver figura 14), observamos cómo las dataciones (Sanjurjo-Sánchez et al. 2014, 2017; Vidal-Romaní et al. 2013) de los depósitos rítmicos y bioespeleotemas (pigotita, evanista y ópalo-A) están generalmente relacionados con períodos húmedos $\mathrm{y}$ probablemente fríos.

Así el desarrollo de los depósitos no sería un proceso continuo, si no que se limitaría a unos episodios climáticos específicos. Aunque no disponemos de datos suficientes, durante los episodios secos y probablemente cálidos, estos depósitos habrían dejado de desarrollarse. La humedad se reduce en todos los niveles de estas cuevas, mejorando su habitabilidad. Aparecen así los diferentes horizontes de ocupación humana como nos muestran las dataciones disponibles (VidalRomaní et al. 2010; Sanjurjo-Sánchez et al. 2012).

Railsback et al. (ib), señalan la existencia de discontinuidades por erosión-disolución en los espeleotemas de las cavidades kársticas de O Courel, coincidiendo con episodios excepcionalmente húmedos. Así, en el caso de los sistemas en rocas plutónicas, entendemos que estos episodios se correspondería con períodos o eventos de reactivación, predominando la destrucción y erosión de los depósitos de pigotita.

Como síntesis de los procesos observados en estas cuevas, la figura 15 muestra sobre una sección teórica de un río de bloques, la zonación y gradación de los procesos en función de la profundidad, pero también su interacción o superposición.

\section{BIBLIOGRAFÍA}

Alonso-Cuevas, F.; Costas-Goberna, J.B.; García-García, E.; García-García, M.; García-Vazquez, C.E.; Groba-González, X.; Míguez-López, A.M.; Pérez Moledo, A.; Rodríguez-Castro, F.; SueiroRodríguez, J.; Vaqueiro-Rodríguez, M.; Vazquez-Vaamonde, D. (1997). Os sistemas de cavidadesde do Folón e Porteliña. Contexto prehistórico de relevancia da zona espeleolóxica G/PO-1. Maúxo, Vigo-Nigrán. Castrelos, vol. 9-10 (19961997). Revista do Museo Municipal "Quiñones de León”. Vigo. pp.37-53.

Boston, P.J. (2004). Extraterrestrial caves. In: Gunn, J. (Ed.), Encyclopedia of Cave and Karst Science. Fitzroy-Dearborn Publishers, Ltd., London, pp. 355-358

Chabert C. \& Courbon, J. (1997). Atlas des cavités non calcaires du monde. Ed. Pre de Mme Carles, Paris.

Eraso, A. \& Pulina, M. (1994). Cuevas en hielo y ríos bajo los glaciares. Mcgraw Hill/Interamericana De España, S.A. Madrid. Pp: 13-17, 67-72.

Kolawole \& Anifowose (2011). Talus caves: Geotourist attractions formed by spheroidal and exfoliation. Ethiopian Journal of Environmental Studies and Management Vol. 4 No.3 2011. DOI:http:// dx.doi.org/10.4314/ejesm.v4i3.1

PCC, 2007. Pennsylvania Cave Conservancy. Cave Database (developed in 1982 by K.D.Wheeland). Penssylvania Cave Conservancy, February 2007 (http:// caves.org/conservancy/pcc/Files/Caves_ PA_Manual_ver_1.pdf)

Rubio-Navas, J.; Corretge, L.G. (1978). VIGO, hoja 223 (04-11), serie MAGNA-50 1:50.000, Servicio de publica- 
ciones - Ministerio de Industria y Energía. Depósito legal: M-6.791-1978.

Sanjurjo-Sánchez, J.; Vidal-Romaní, J.R.; Vaqueiro-Rodirguez, M..; CostasVazquez, R. \& Grandal-D'anglade, A. (2013). TL estimation of ages of pottery fragments recovered from granite caves in the NW coast of Spain. Cadernos Lab. Xeolóxico de Laxe. Coruña. 2013. Vol. 37, pp. $73-88$.

Railsback, L.B.; Liang, F.; Vidal-Romaní, J.R.; Grandal-D'anglade, A.; Vaqueiro-Rodríguez, M.; Santos-Fidalgo, L.; Fernández-Mosquera, D.; Cheng, H.; Edward, L. (2011)- Petrographic And Isotopic Evidence For Holocene LongTerm Climate Change And ShorterTerm Environmental Shifts From A Stalagmite From The Serra Do Courel Of Northwestern Spain, And Implications For Climatic History Across Europe And The Mediterranean. Palaeo 3 (Geography-Climatology-Ecology). 2011. PP: $1-56$

Sanjurjo-Sánchez, J.; Vidal-Romaní, J.R.; Vaqueiro-Rodríguez, M.; CostasVázquez, R.; Arce-Chamorro, C. (2014). Luminiscence dating of speleothems from granite caves. XIII Reunión de la Sociedad Española de Geomorfología, Cáceres 9-12 septiembre 2014. 470-473.

Sanjurjo-Sánchez, J.; Vidal-Romaní, J.R.; Vaqueiro-Rodríguez, M.; GrandalD'anglade, A. (2012). Datación por termoluminiscencia de cerámicas de cuevas y cavidades graníticas en el NW de la Penínusla Ibérica. Actas do IX congreso Ibérico de Arqueometría (Lisboa, 2011). Estudos aqueológicos de Oeiras, vol. 19: 275-280.

Sanjurjo-Sánchez, J.; Arce-Chamorro, C.; Vidal-Romaní, J.R.; Vaqueiro- Rod- ríguez, M.; Barrientos, V; Kaal, J. (2017). Al-bearing organic speleothems in granite caves of NW Iberia: characterization and genesis. Geomorphology (in print).

Stone, R.W. (1953). Description of Pennsylvania's Undeveloped Caves. National Speleological Society Bulletin, Vol. 15: 51-137.

Twidale, C.R. \& Vidal-Romaní, J.R. (2005). Landforms and Geology of Granite Terrains. A.A.Balkema Publishers Leiden. 352 pag.

Urban, J. \& Oteska-Budzyn, J. (1998). Geodiversity of pseudokasrt caves as the reason for their scientific importance and motive of protection. GEOLOGICA BALCANICA, 28 3-4, Soifa, Decem. 1998, p.163-166.

Vaqueiro-Rodríguez, M. \& Vidal-Romaní, J.R. (2014). Granite Pseudokarst. Proceedings XIII Reunión Nacional de Geomorfología, Cáceres 2014. pp:482-485.

Vidal-Romaní, J.R. \& Twidale; C.R. (1998). Formas y Paisajes Graníticos. Servicio de Publicacións Universidade de A Coruña. 412 pag.

Vidal-Romaní, J.R. \& Vaqueiro-Rodríguez, M. (2007). Types of granite cavities and associated speleothems: genesis and evolution. Nature Conservation vol. 63 (6) 2007. Institute of Nature Conservation Polish Academy of Sciences. Kraków, Poland. pp: 41-46.

Vidal-Romaní, J.R.; Sanjurjo-Sánchez, J.; Vaqueiro-Rodríguez, M.; FernándezMosquera, D. (2010). Speleothem development and biological activity in granite caves. Géomorphologie: Relief processus, environnement, 2010. nr. 4, p. 337-346.

Vidal-Romaní, J.R.; Sanjurjo-Sánchez, J.; Grandal-D'anglade, A.; Vaqueiro-Rodríguez, M.; Fernández-Mosquera, D. 
(2010). Geocaracterización de yacimientos arqueológicos en medio sedimentario: cronología absoluta y relativa. In: López Díaz A.J., Ramil Rego E. (Eds.): Arqueoloxía: Ciencia e Restauración. Monografías, 4. Museo de Prehistoria e Arqueoloxía de Vilalba, Vilalba (Lugo),: 7-19

Vidal-Romaní, J.R.; Sanjurjo-Sánchez, J.; Vaqueiro-Rodríguez, M.; González-
López, L.; López-Galindo, M.J. (2013). Speleothems in cavities developed in magmatic rocks. In: Filippi M., Bosák P. (Eds.), Proceedings of the 16th International Congress of Speleology, July 2128, vol. 3: 479-482.

Wright, V.P. (1989). Terrestrial stromatolites and laminar calcretes: a review. Sedimentary Geology, 65: 1-13. 


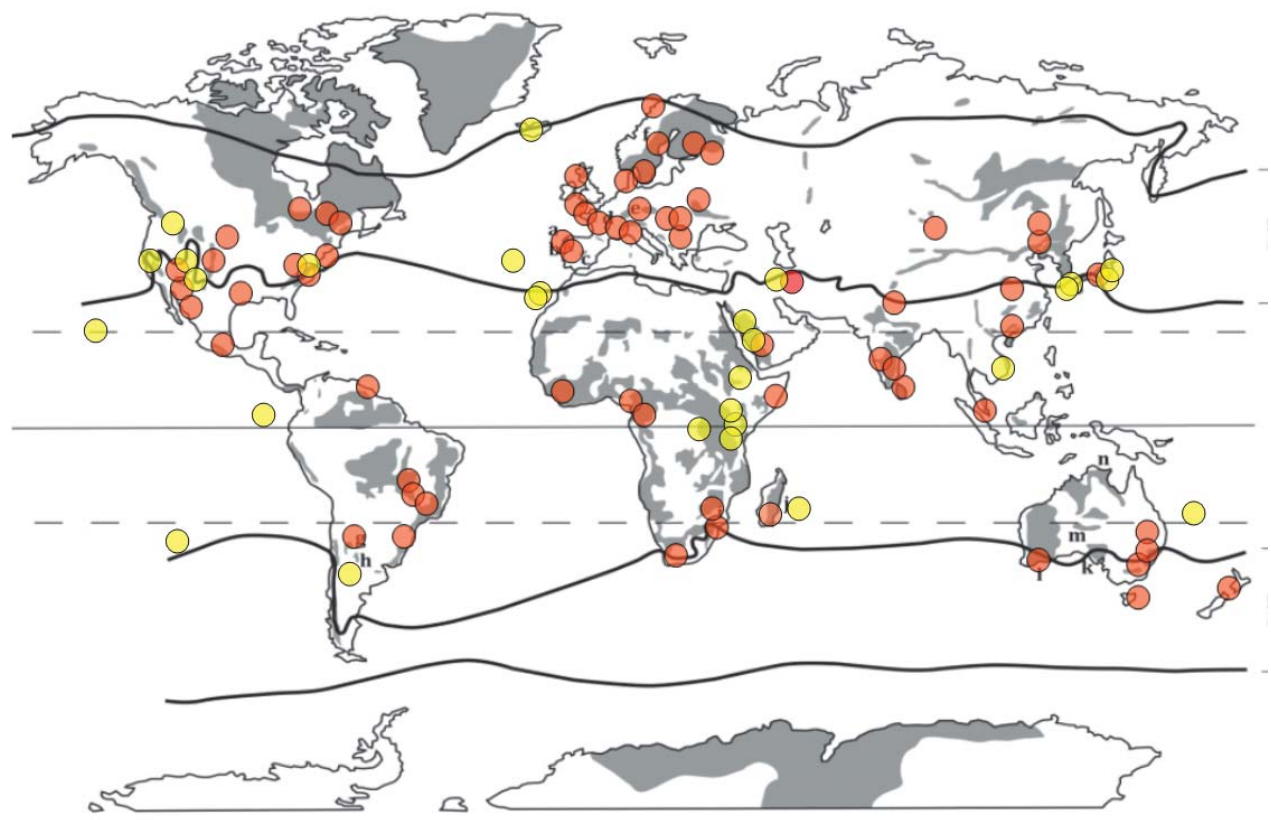

Fig. 1. Distribución mundial de zonas con cavidades en rocas magmáticas. Los circulos rojos sitúan zonas en las que se han identificado cavidades en rocas plutónicas. Con círculos marillos se han marcado, a grosso modo, las zonas dónde se localizan cavidades en rocas volcánicas.

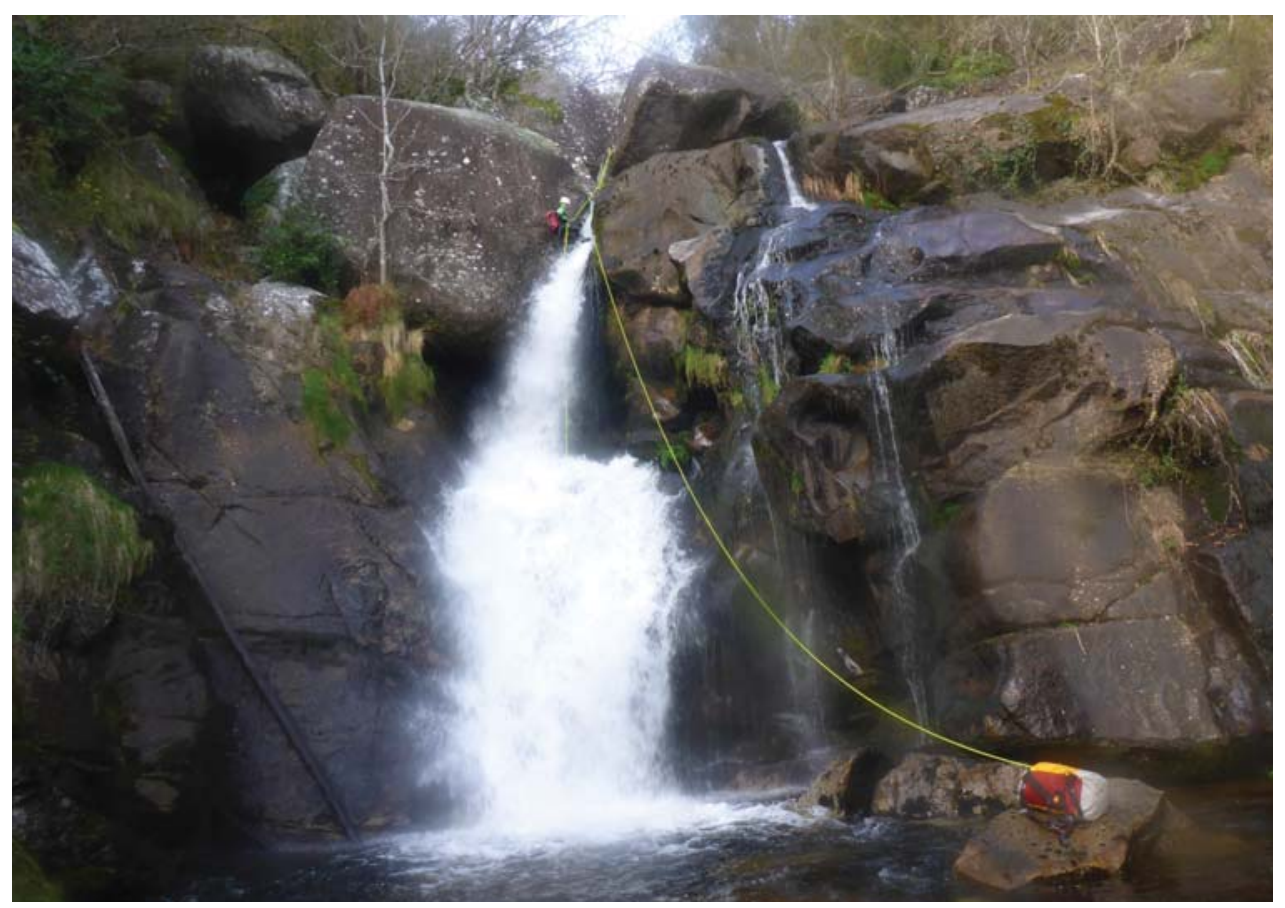

Fig. 2. Los ríos de bloques y los cañones techados (versión estructural de los ríos de bloques) suelen presentar una surgencia en la cota inferior de la colada de bloques. Como ejemplo la surgencia del sistema de Figueiras en Mondoñedo: El acuífero se encuentra en carga, y los excesos de caudal que no pueden ser transferidos a través del sistema, circulan por encima de la colada de bloques formando una cascada estacional sobre la surgencia permanente del Figueiras (chorro grueso a mitad de altura). Fotografía cortesía de Carlos Ares (G.E.S. Irmandiños, 2017). 


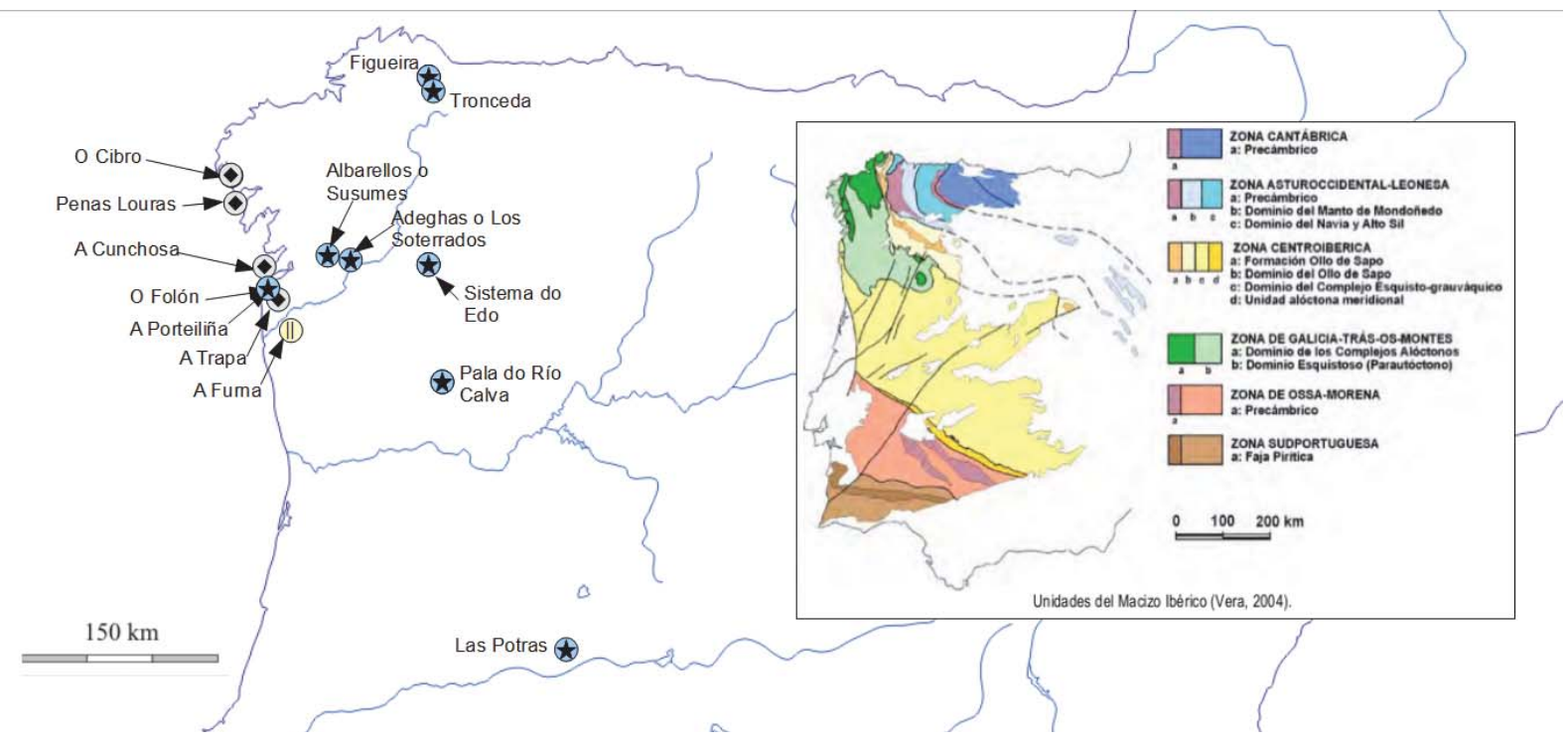

Fig. 3. Situación de los principales ríos de bloques (rombo) y cañones techados (asteriscos) localizados en la zona de estudio. Además de los 12 sistemas que se describen en este artículo, se señalan otros sistemas próximos, alguno estructural de gran desarrollo $(\|)$.

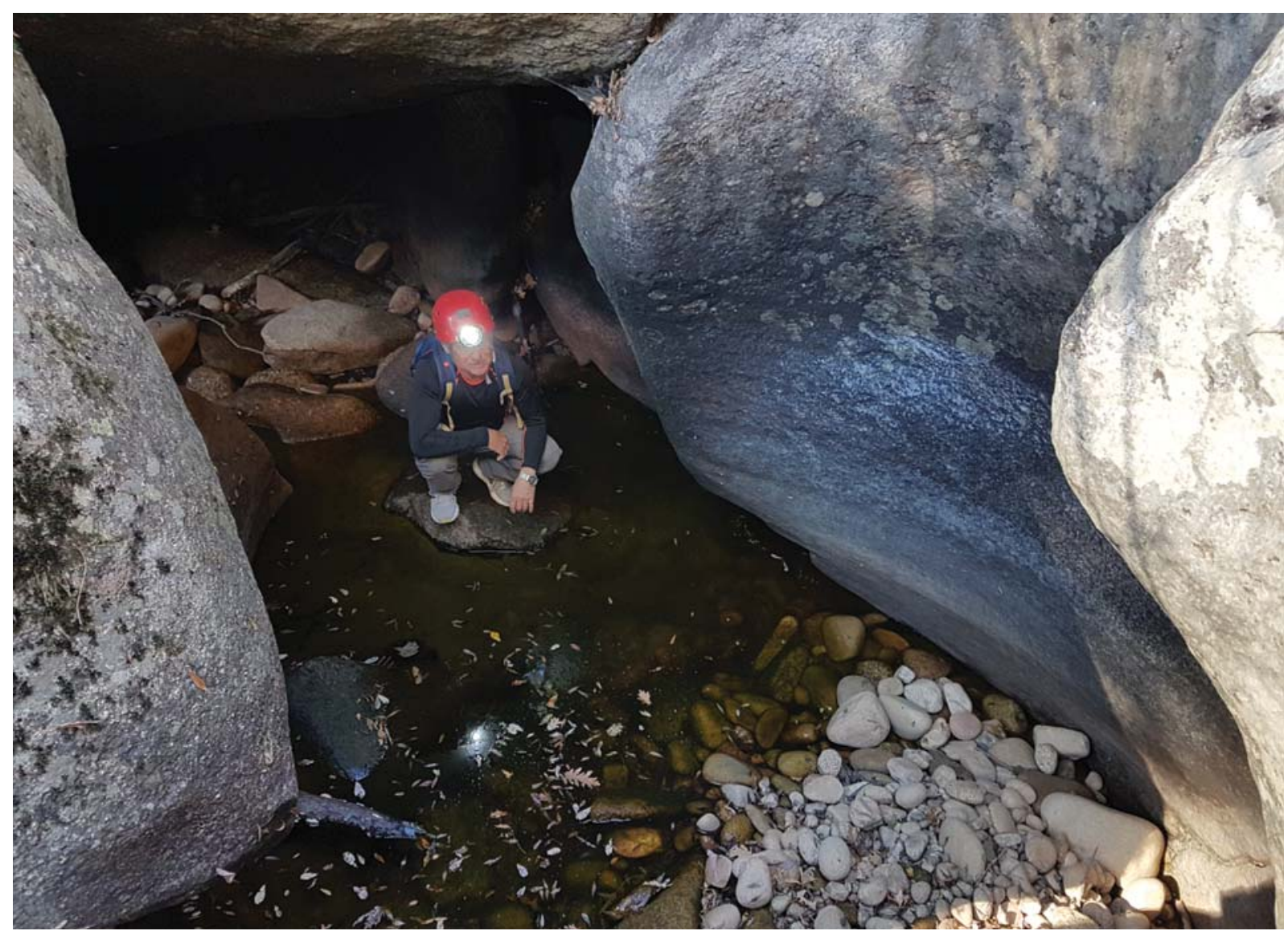

Fig. 4. Sistema do Río Calva, en Santa Valha, Portugal. Marmitas en las proximidades del sumidero y que dan acceso al interior de esta cavidad. Fotografía M. Vaqueiro, 2017. 


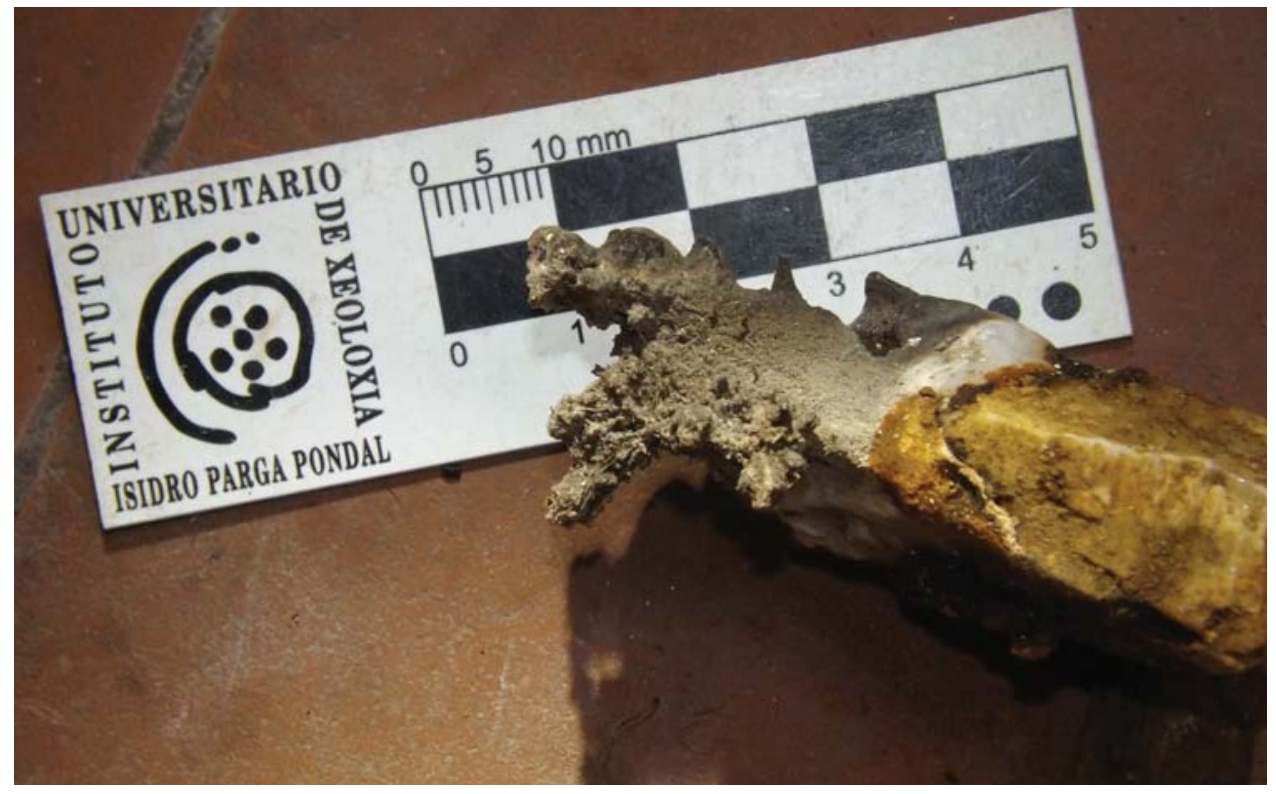

Fig. 5. Sistema de A Cunchosa, en Aldán, Cangas do Morrazo, provincia de Pontevedra, España. Bioespeleotemas de ópalo-A desarrollados en el extremo de un fenocristal. Fotografía de muestra extraída para su estudio. M. Vaqueiro, 2015.

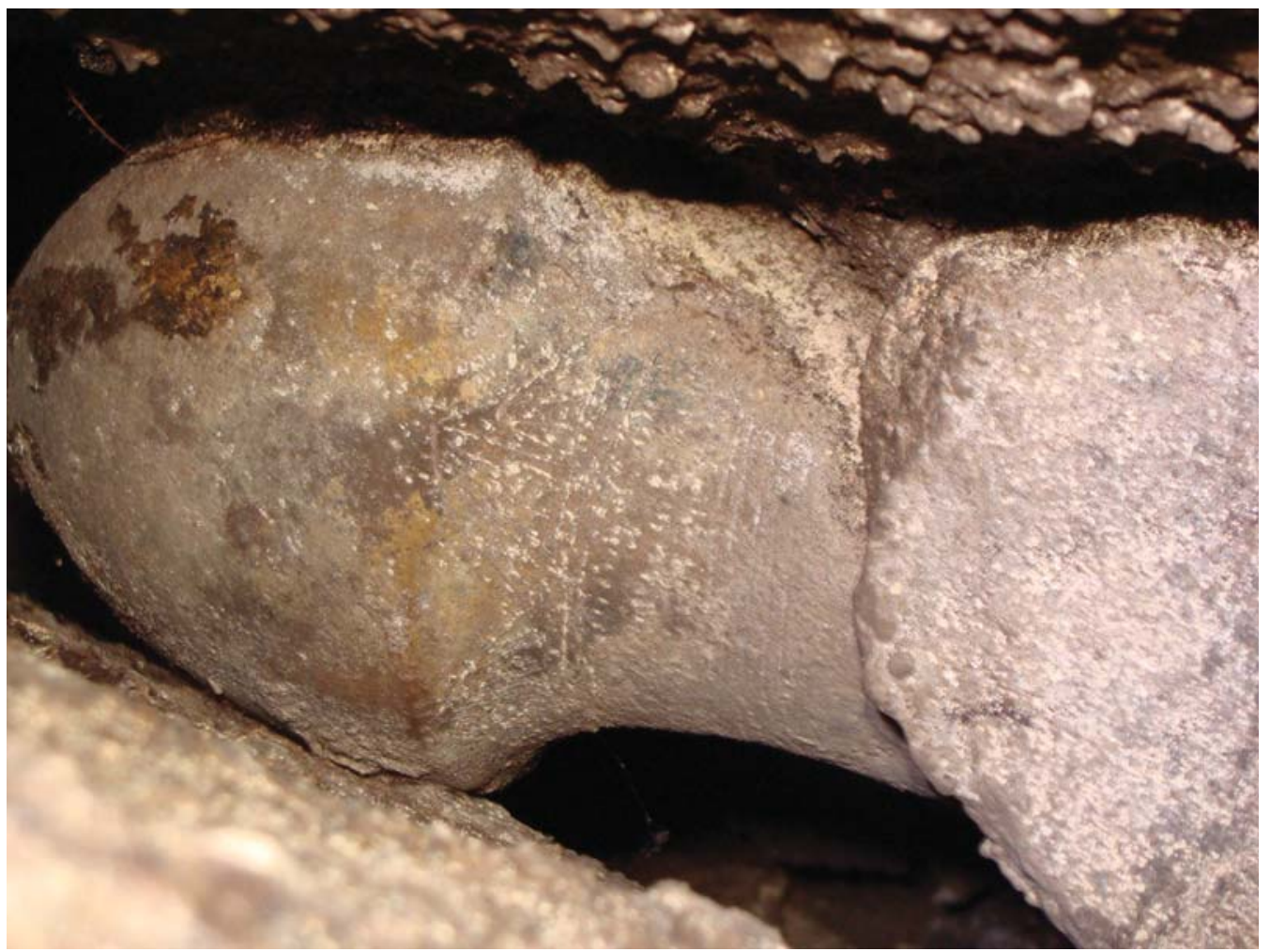

Fig. 6. Sistema de Los Soterrados o Adeghas en Partovia. Carballiño, provincia de Ourense, España. Vaso cerámico decorado localizado in situ, en el tránsito entre los niveles altos de la colada de bloques y los primeros paleoniveles del sistema próximos al sumidero del río Barón. Material depositado en el Museo Arqueológico Provincial de Ourense. Fotografía M. Vaqueiro, 2012. 


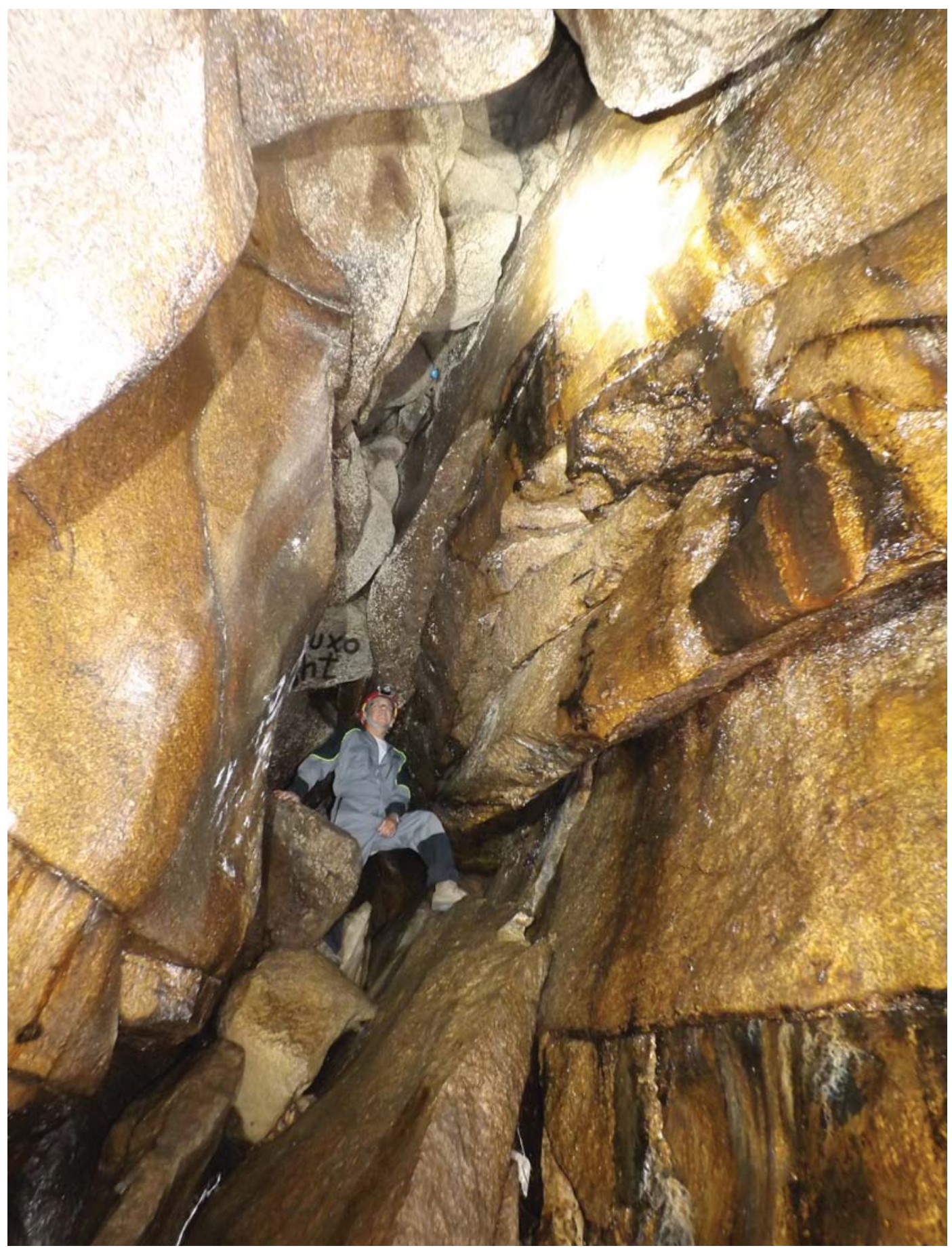

Fig. 7. Sistema de O Folón, Fragoselo-Coruxo, Vigo, provincia de Pontevedra, España. El cañón estructural de esta cueva se adaptada en general a la banda de cizalla asociada a una falla de desgarre de dirección $\mathrm{N} 170^{\circ} \mathrm{E}$, con un curso definido en discontinuidades subverticales de direcciones $\mathrm{N} 160^{\circ} \mathrm{E}, \mathrm{N} 60^{\circ} \mathrm{E}, \mathrm{N} 60^{\circ} \mathrm{W}$. Este tramo de la cueva de paredes sinuosas y pulidas, mantiene la dirección $\mathrm{N} 160^{\circ} \mathrm{E}$. El curso se localiza aproximadamente a $12 \mathrm{~m}$ de profundidad con respecto al nivel de techo del río de bloques. El curso se ha techado a partir de un deslizamiento de la estructura de lajas de un domo situado en la parte derecha de la fotografía. En la pared opuesta, lado izquierdo de la fotografía, que no ha sufrido desplazamientos, se preservan marmitas de pequeño diámetro pero con un desarrollo vertical de $8 \mathrm{~m}$. Fotografía M. Vaqueiro, 2016. 


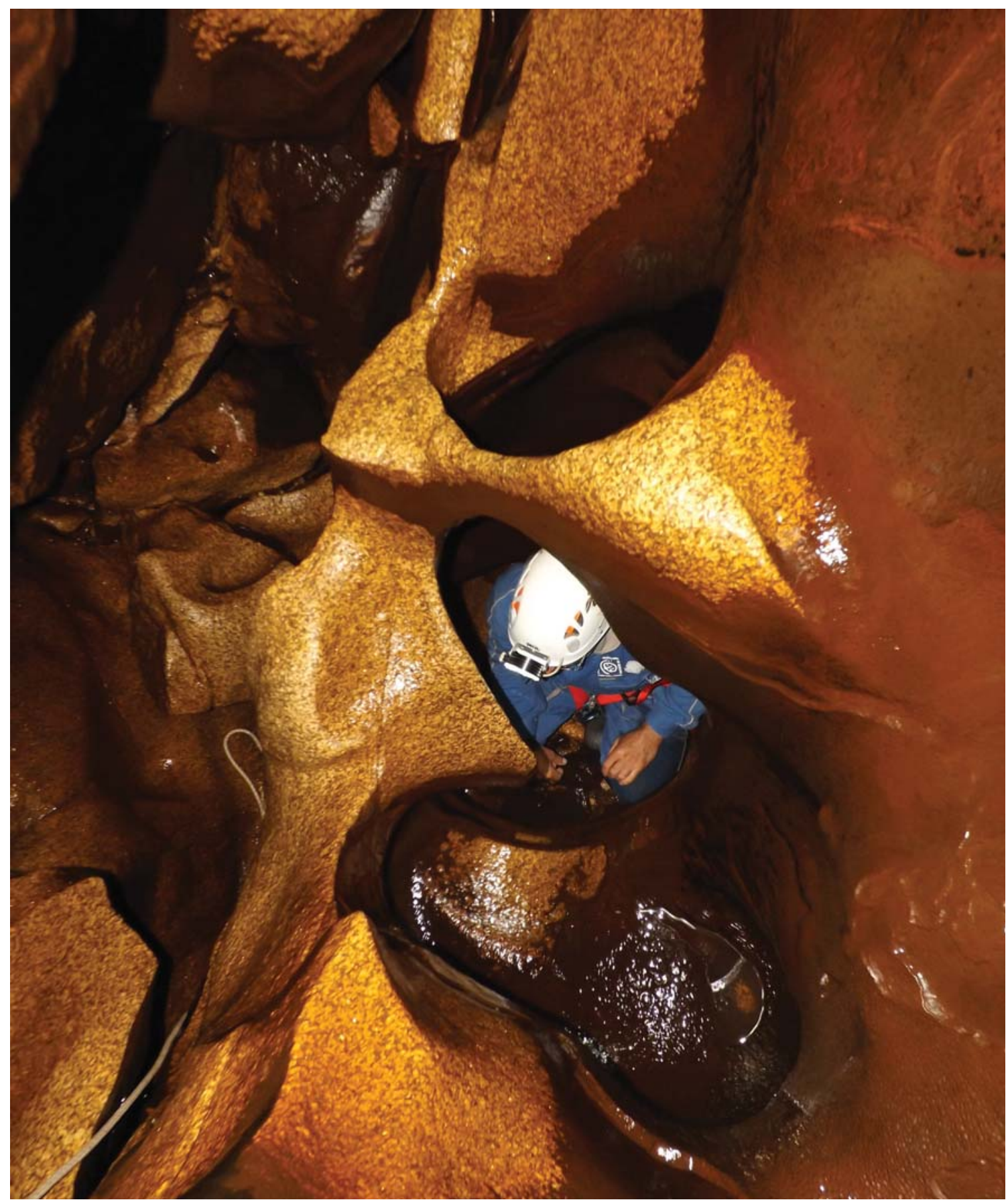

Fig. 8. Sistema de A Trapa, Ribadelouro, Tui, provincia de Pontevedra, España. El plano de la falla inversa cuyo movimiento se estima provocó el deslizamiento de $119.453 \mathrm{~m}^{3}$ de roca sobre el río S. Simón, define un tramo de curso subterráneo de carácter estructural verticalizado por cambios bruscos de gradiente. El río subterráneo forma una cascada de más de $8 \mathrm{~m}$ de altura cuyo lateral esta caracterizado por varios paleoniveles escalonados, con formas de erosión de diversa entidad, incluyendo interesantes conjuntos de marmitas como las de la fotografía, que se encuentran despegadas del lecho actual. La patina que forra parcialmente las marmitas y las superficies pulidas son los restos de una colada de pigotita con microgours superpuestos que en la actualidad está siendo destruida por la fuerza erosiva del curso activo. La misma colada cubre la bóveda, paredes e inclusive se extiende por debajo de estas marmitas formando un conglomerado con matriz de pigotita. Fotografía M. Vaqueiro, 2014. 


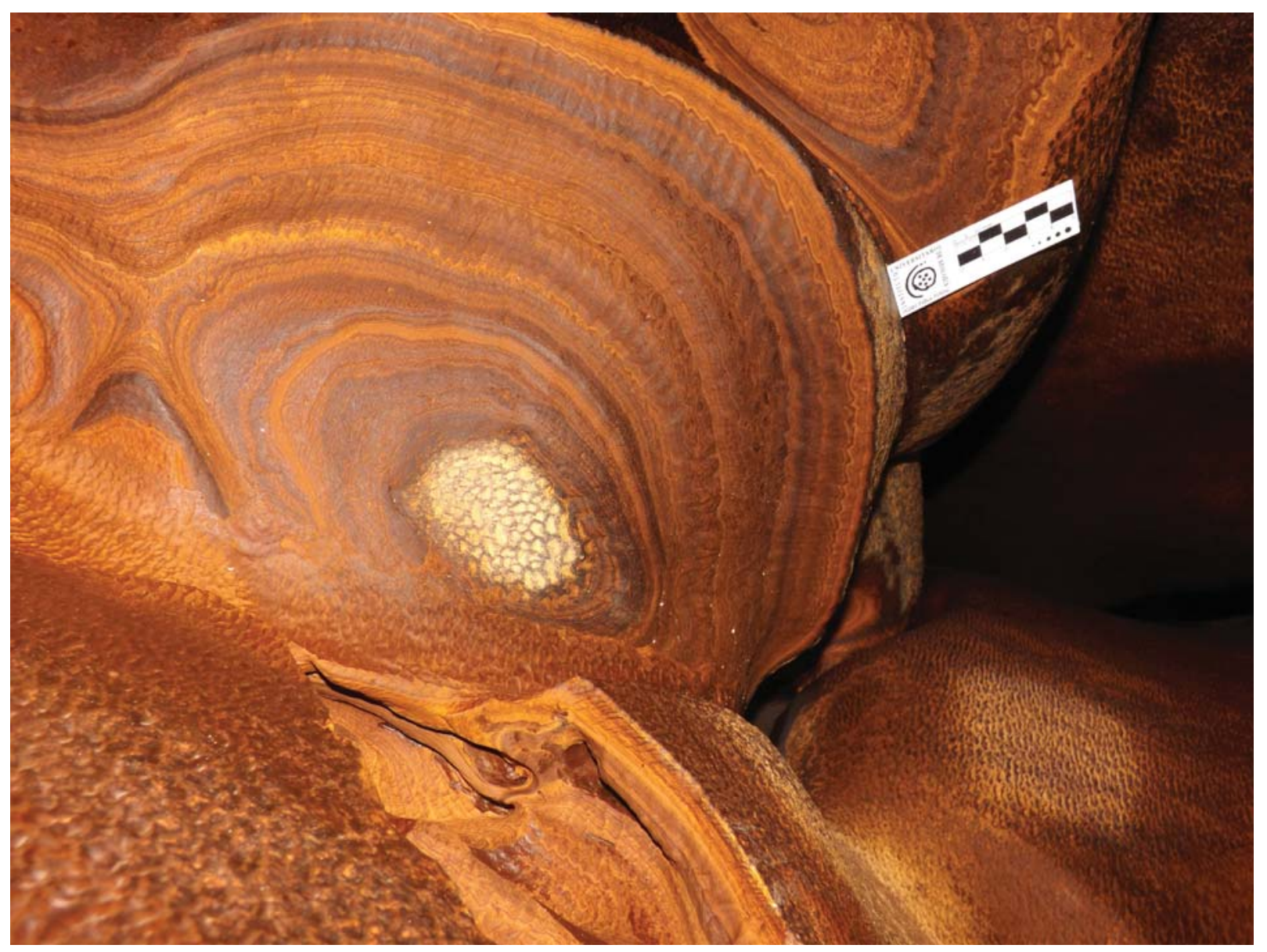

Fig. 9. Sistema de A Trapa, Ribadelouro, Tui, provincia de Pontevedra, España. Detalle de la colada de pigotita de uno de los paleoniveles reactivados. Estos depósitos son tipo formas de flujo con microgours superpuestos cubriendo la totalidad de la superficie. Este depósito habría dejado de crecer en el 2750-2050 cal.yrBP (VIDAL-ROMANÍ et al., 2010). La reactivación del paleonivel provoca la ciculación estacional del agua sobre el depósito, que es parcialmente erosionado. La acanaldura permite observar la estructura rítmica del depósito, formado por capas claras y oscuras alternas. Cerca del escalímetro se puede observar un dentado visible en la ritmita que se corresponderían con microgours fosilizados durante el crecimiento del depósito. Fotografía M. Vaqueiro, 2008. 


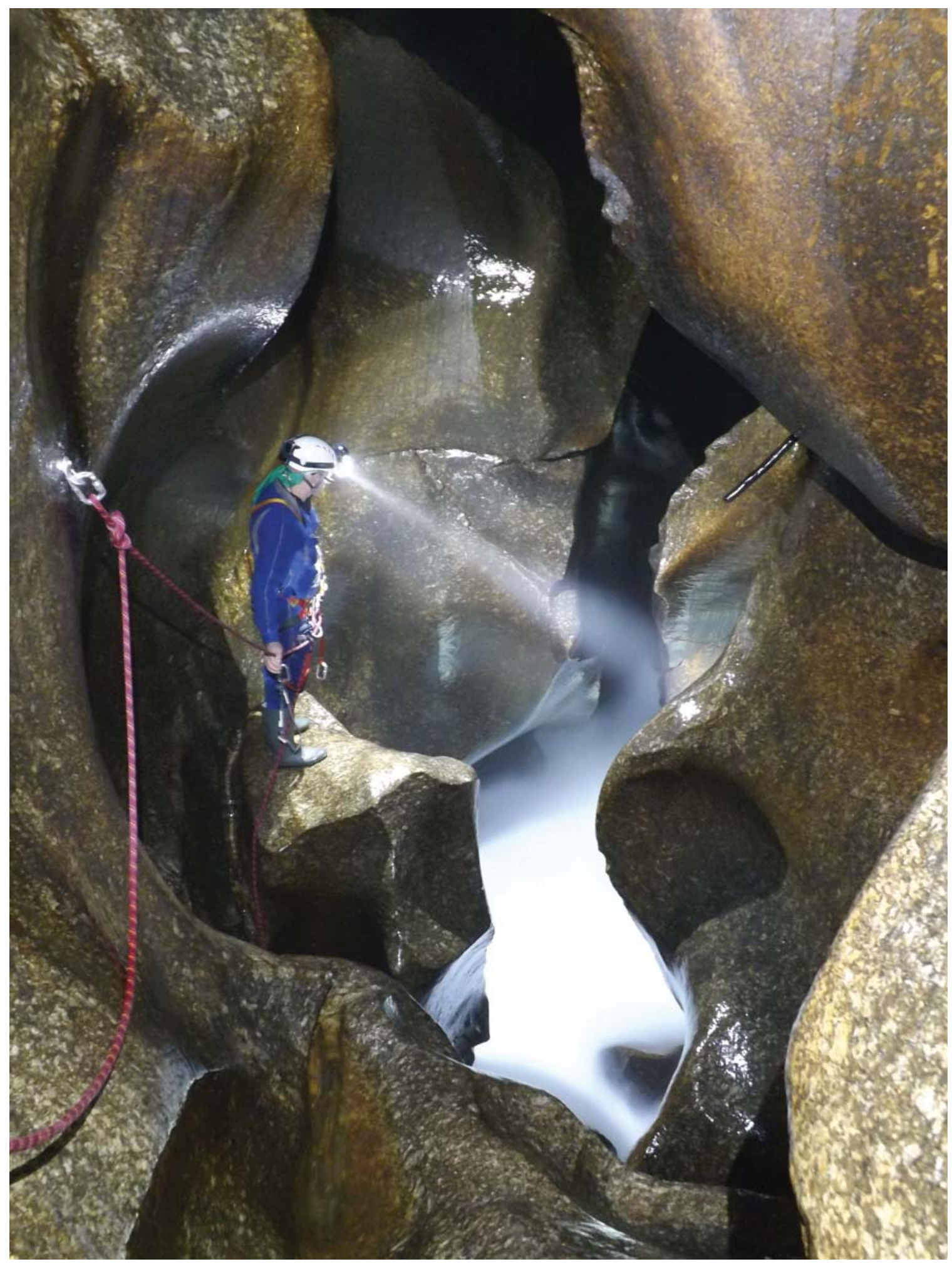

Fig. 10. Sistema de Albarellos o Susumes en Beresmo, Avión, provincia de Ourense, España. Vista del cañon del sistema durante su ciclo de carga otoñal $(15.000 \mathrm{l} / \mathrm{s})$. El lecho se sitúa entre 6 y $8 \mathrm{~m}$ por debajo del espeleólogo. Puede apreciarse como el cañón está definido por la coalescencia de marmitas de $11 \mathrm{~m}$ de desarrollo vertical. Fotografía M. Vaqueiro, 2014. 


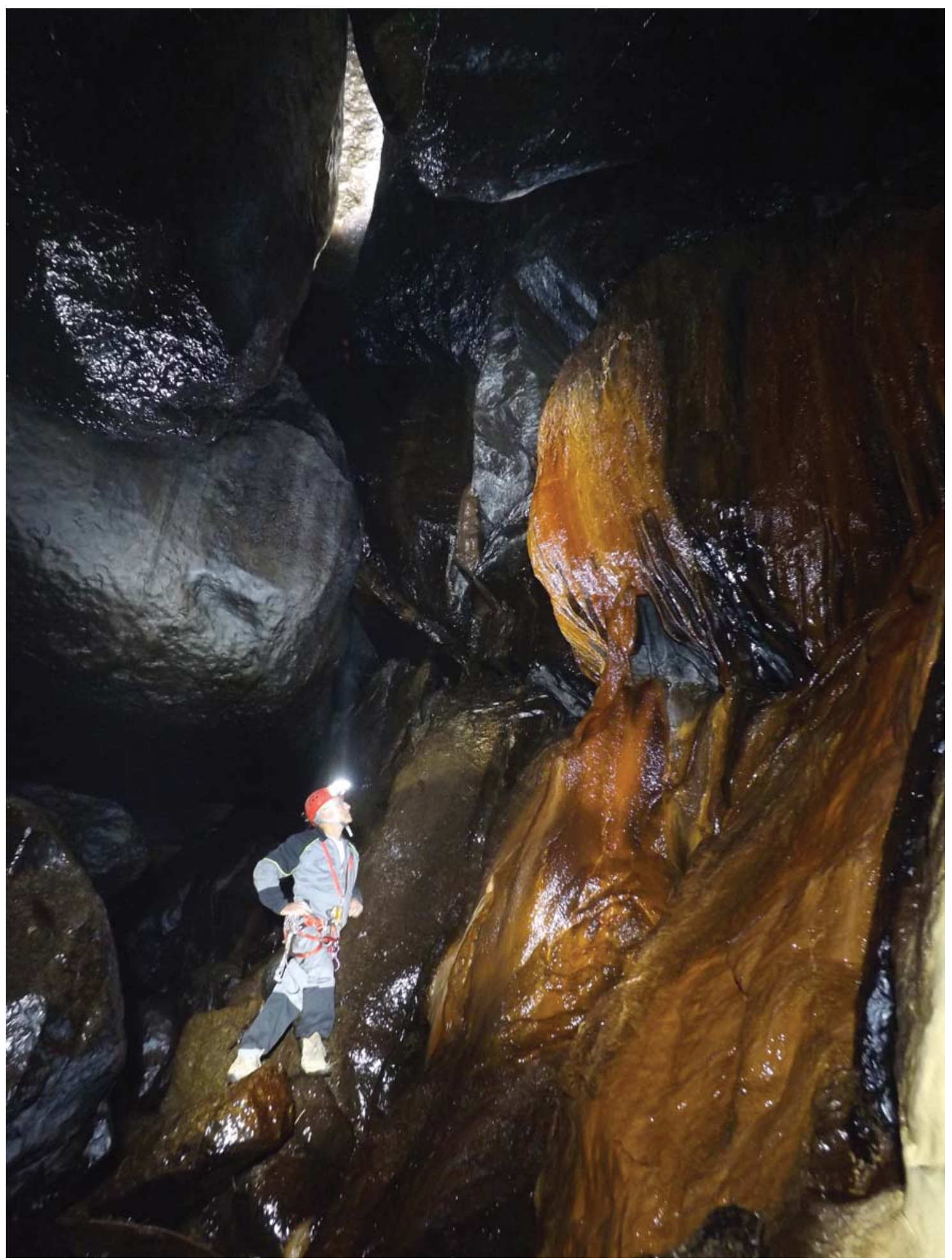

Fig. 11. Sistema de Tronceda, O Tronceda, Mondoñedo, provincia de Lugo, España. En la fotografía una de las salas del sistema con mayor altura y amplitud. El lecho del curso subterráneo se sitúa unos $5 \mathrm{~m}$ por debajo del espeleólogo. Esta colada de pigotita destaca por las formas compuestas (draperies) situadas en su zona superior. Aunque visualmente la colada parece bien conservada, los microgours están parcialmente erosionados. Fotografía M. Vaqueiro 2016. 


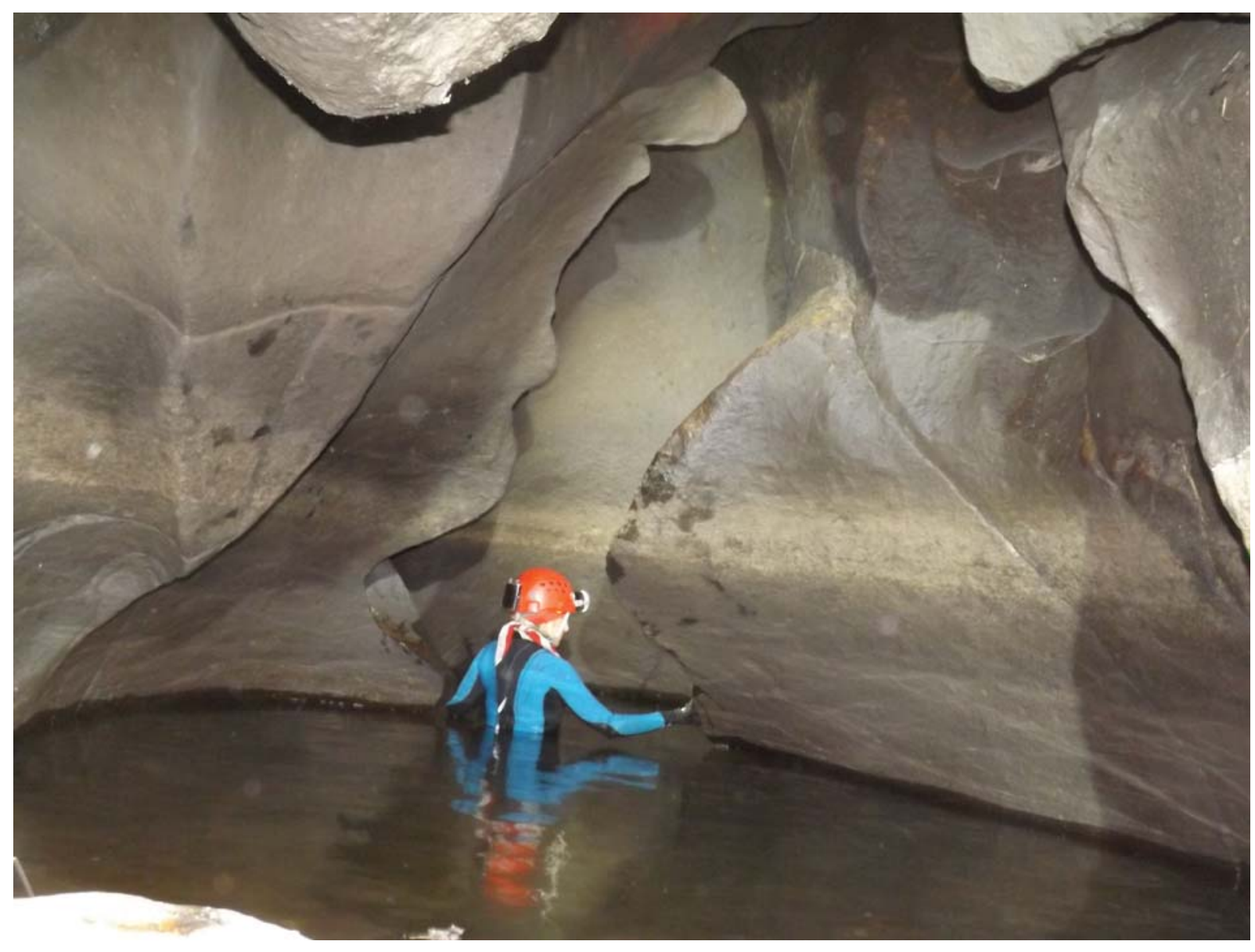

Fig. 12. Sistema de Las Potras de Montehermoso, Montehermoso, provincia de Cáceres, España. La fotografía muestra una de las grandes marmitas situadas bajo el sumidero de Las Potras. El curso está definido por un canal sinuoso producido por la coalescencia de marmitas adyacentes. Puede apreciarse la compleja sección transversal que perfila el cañón en esas interseciones. Fotografía M. Vaqueiro, 2017. 


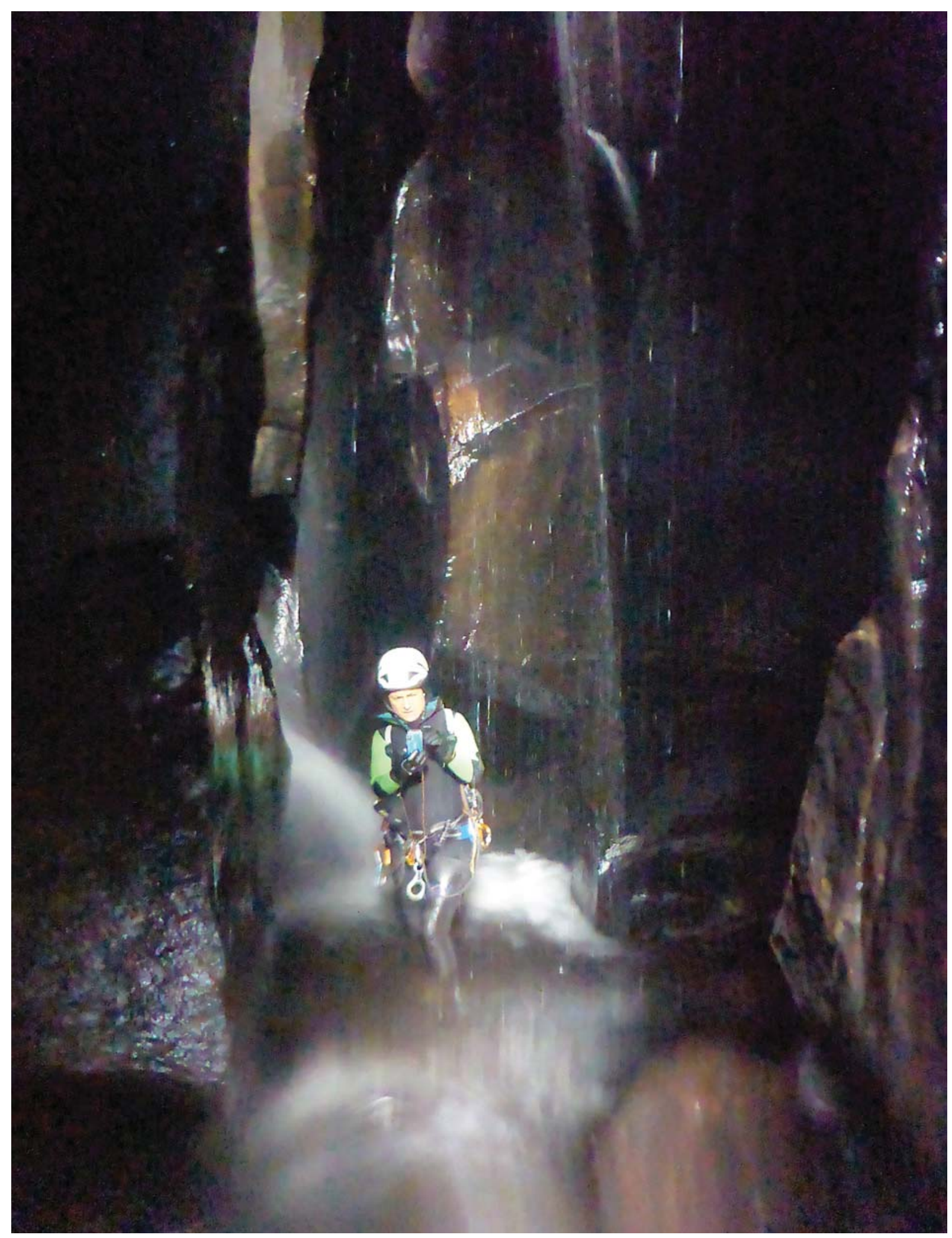

Fig. 13.Sistema del río Edo, Castrocaldelas, provincia de Ourense, España. Fotografía Carlos Ares (G.E.S. Irmandiños, 2017). 


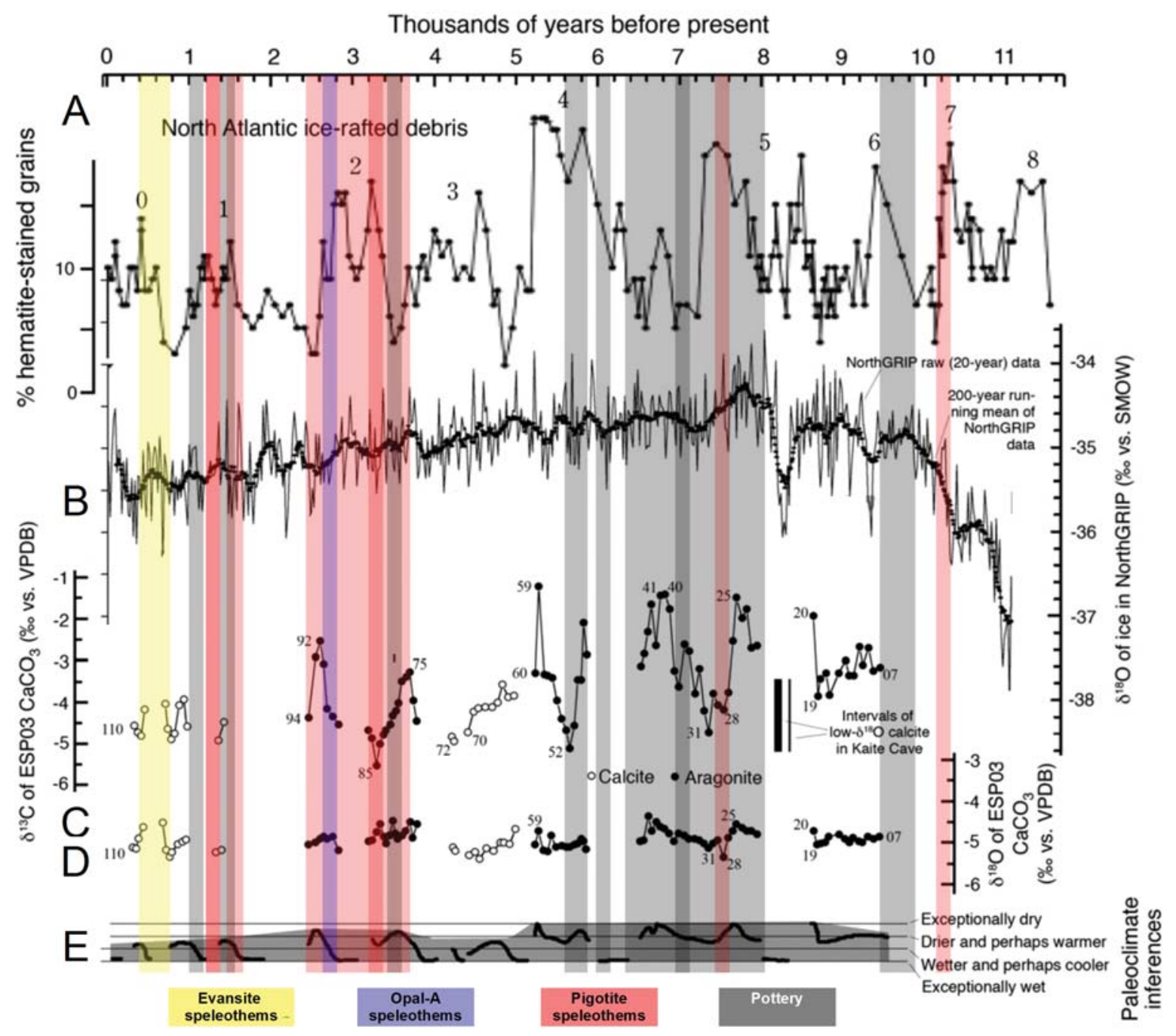

Fig. 14. Tomando como referencia la reconstrucción paleoclimática de RAILSBACK et al. (2011) para el Holoceno en Galicia, y con el objeto de evaluar posibles dependencias climáticas, superponemos las dataciones disponibles para los espeleotemas de opal-A (blue), evansita (yellow) y pigotita (red) obtenidos en cinco cuevas en granito del NW de la Península Ibérica. También se incluyen las dataciones de materiales arqueológicos (gray) localizados en estas cuevas. La figura muestra como los depósitos rítmicos (biominerales) parecen estar relacionados con periodos húmedos y probablemente fríos, mientras que el uso de las cuevas por el ser humano parece asociado a períodos secos y posiblemente cálidos. A. Plot of abundance of ice-rafted debris in the North Atlantic (Bond et al., 2001). B. Plot of stable isotope data from Greenland ice cores from Johnsen et al., 2001. C \& D. Stable isotope data from ESP03. Small numerals next to symbols for stable isotope data indicate numbers of specific samples. E. Qualitative interpretation of changing climatic conditions. 


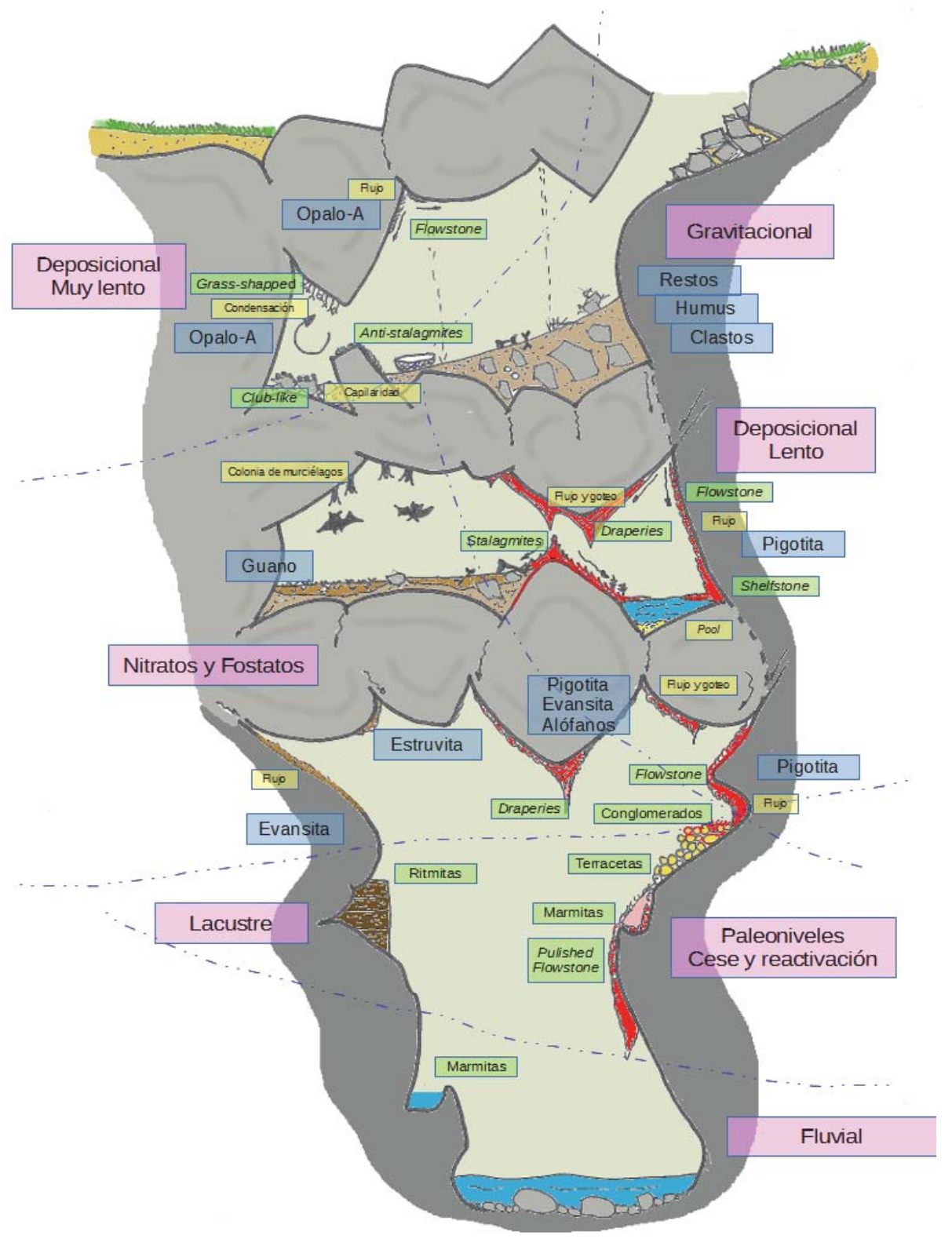

Fig. 15. Sección esquemática de un río de bloques que rellena parcialmente y techa un curso de agua con cañón en roca. Las variaciones de caudal del curso subterráneo determinan el dominio fluvial de la cueva. Por encima de esta zona existen paleoniveles que pueden presentar formas de erosión fósiles, pequeñas terrazas, e inclusive restos de ritmitas asociadas a procesos lacustres. En algunos casos se produce una interacción entre estas formas y los bioespeleotemas que pasan a fosilizar las formas más antiguas, inclusive formando conglomerados con matriz de pigotita. Es una zona que puede presentar reactivación y por tanto se puede producir una exhumación de las formas antiguas. Por encima de este nivel, en el tránsito entre el cañón y el río de bloques, suele aparecer una zona de circulación de aguas lentas. Infiltraciones y manantiales que dan lugar a depósitos de pigotita, pero también de estruvita o evansita cuando existen guanos que aporten nitratos y fosfatos. Son zonas con temperaturas medias más estables y subatenuadas con respecto a las oscilaciones térmicas exteriores, razón por la que suelen observarse colonias de quirópteros. En el nivel superior, más próximo a superficie parecen predominar los procesos gravitacionales, con caída de materiales y fragmentos de roca al interior de las cavidades. Son espacios que varían de semi-oscuros a oscuros, dónde rápidamente se alcanzan elevadas humedades relativas. Aparecen depósitos de biominerales de ópalo-A asociados a zonas de condensación preferente, a circulación fisural o escorrentía muy lenta. Fuente Vaqueiro-Rodríguez (2017). 